\title{
Computational analysis of some degree based topological indices of cubic structured tungsten trioxide $[1, m, n]$ nanomultilayer
}

\author{
M. S. Duraisami*, K. Parasuraman \\ PG \& Research Department of Physics, Poompuhar College (Autonomous), Melaiyur - 609107, Tamilnadu, India \\ Affiliated to Bharathidasan University, Tiruchirappalli \\ *tharmamithran@gmail.com
}

PACS 02.10.0x, 61.48.-c

DOI 10.17586/2220-8054-2020-11-5-501-509

\begin{abstract}
Topological indices are numerical invariants of molecular graphs and are beneficial for predicting the physicochemical properties of chemical compounds. In this view, a topological index can be considered as a score function which maps each molecular structure to a real number. In the past two decades, tungsten trioxide $\left(\mathrm{WO}_{3}\right)$ nanostructures have been extensively studied for their diverse technological applications. They have received greater attention by researchers, owing to their novel functionalities and unique physicochemical properties. We, for the first time, compute the Sum Connectivity index, Variable Sum index, ABC index, Harmonic index, Ordinary Geometric Arithmetic index, SK indices, Forgotten index, Symmetric Division index, Augmented Zagreb index, Inverse sum index, IRM index, Modified second Zagreb index, Inverse Randić index, Albertson and Bell topological indices of cubic structured $\mathrm{WO}_{3}[l, m, n]$ nanomultilayer. We also present a graphical analysis of all indices with respect to the dimension of this nanomultilayer.
\end{abstract}

Keywords: topological index, chemical graph, cubic $\mathrm{WO}_{3}$, nanomultilayer.

Received: 31 August 2020

Revised: 8 September 2020

\section{Introduction}

Let $G=(V, E)$ be a molecular graph of order $p$ (number of vertices) with size $q$ (number of edges). Denote $u v$, the link (edge) joining the nodes (vertices) $u$ and $v$. The degree of a vertex $u \in V(G)$ is denoted by $d_{u}$ and is the number of vertices that are adjacent to $u$. Molecular graphs are a unique type of chemical graphs, which describe the constitution of molecules [1]. Molecular graph considered in this article is finite, undirected, connected, loopless, and without multiple edges.

\subsection{Background}

Testing of new reagents in chemical physics and physical chemistry is always a major concern. One of the prominent strategies to address this issue is the graph theoretic approach, which performs to model the characteristics of novel and proposed chemical compounds to save time and costs. Chemical graph theory plays a crucial role in molecular topology and computational nanomaterials to determine the structure of molecular graphs [2-4]. Topological characterization is a standout approach provided by chemical graph theory to predict certain physicochemical properties like molecular weight, density, risk assessment, toxicity and determine regularity decisions and so forth [2-6]. Topological indices (molecular descriptors) are numerical values associated with chemical constitution and are applied in the development of quantitative structure-activity relationships (QSARs), Quantitative Structure Property Relationships (QSPRs) and Quantitative Structure-Toxicity Relationships (QSTRs) [7, 8]. They preserve the symmetry of molecular structures and act as a bridging tool between mathematics and chemistry. Until recently, several kinds of topological indices are introduced like distance-based, degree-based and spectrum-based indices and so on. Among them, degree based topological indices are robust in nature, because they can be directly derived from the structure of chemical graphs. The concept of topological indices in chemical graph theory was first introduced by Weiner in 1947, to predict the heats of formation, chromatographic retention time, boiling point and strain energy [2]. In recent times, many authors employed topological indices of various nanostructures involving Pent-Heptagonal Nanosheets [9], polyhex nanotubes [10] and nanostar dendrimers [11]. For more about the significance of topological indices in molecular chemistry and the graph theoretical tools used in this article, we refer $[12,13]$ and references therein. 


\subsection{Degree based Topological Indices}

In this part, we shall enumerate some degree-based topological indices (as explicated in Table 3) that will be needed in the main result section. Gutman et al. [3] established a pair of topological indices namely, first Zagreb $\left(M_{1}(G)\right)$ and second Zagreb $\left(M_{2}(G)\right)$ indices for predicting total $\pi$ electron energy of compounds. In mathematical chemistry, there is a large number of topological indices of the form

$$
T I=T I(G)=\sum_{x_{i}} F\left(d_{i}, d_{j}\right) .
$$

Another important degree-based topological index called Randić index (connectivity index or branching index), which is given by Milan Randić in 1975 [32]. It has found manifold applications in drug designing field. Later, Amić et al. [29] proposed the generalized version of Inverse Randić index (for any real number $\alpha$ ). For $\alpha=-1, R R_{\alpha}$ turns out to be a second Zagreb index; for $\alpha=1, R R_{\alpha}$ will be a modified second Zagreb index and $R R_{\alpha}$ becomes a Reciprocal Randić index if $\alpha=-\frac{1}{2}$.

\subsection{A brief sketch on $\mathrm{WO}_{3}$ nanomaterial}

Today has witnessed the prompt advancements in nanotechnology, which keeps in pace with the emergence of novel nanomaterials and interdisciplinary approaches. $\mathrm{WO}_{3}$ is one such nanomaterial which has drawn considerable attention of research community due to their various applications in chemical sensors, field emission devices, electrochromic, photocatalysts [33] and photo-electrochemical water splitting [34]. For more details we refer [35] and references therein.

\subsection{Proposed work and organization}

Motivated by the formation of $\mathrm{WO}_{3}$ nanomultilayer reported in [36], here, we construct a molecular graph for cubic $\mathrm{WO}_{3}$ nanomultilayer and compute certain degree based topological indices to reveal its mathematical aspects. The partitions of the edge set and the vertex set of cubic $\mathrm{WO}_{3}$ nanomultilayer have been well discussed in Section 2. In Section 3, we established our new results about cubic $\mathrm{WO}_{3}$ nanomultilayer in terms of the parameters $l, m$ and $n$. In order to disclose the trends of dependency among the values of indices and the dimensions of the nanomultilayer, some relevant graphical representations are provided in Section 4.

\section{Methods}

It is evident from Fig. 1 and Fig. 2 that, each tungsten atom is closely bound to six oxygen atoms, and each oxygen atom and two tungsten atoms are nearly adjacent, then each tungsten atom is a sub-neighbor with another one. As seen in Fig. 2(a), the intervening portion between two horizontal linear arrangements of connected tungsten trioxide molecules can be taken as a single row $(l=1)$. The same vertical alignment of this pattern forms a single column $(m=1)$ and these two parameters joined together to form a single layer $(n=1)$. Consider a 3-D cubic system of $\mathrm{WO}_{3}$ nanomultilayer with $l$ rows, $m$ columns and $n$ layers, and each layer contains $l$ rows and $m$ columns as shown in Fig. 3. Such a typical molecular system, atoms and bonds can be represented by vertices and edges, respectively. We reserve the notation $\mathrm{c}-\mathrm{WO}_{3}[l, m, n]$ for cubic $\mathrm{WO}_{3}$ nanomultilayer, where $l, m, n \geq 1$. The construction of $\mathrm{c}-\mathrm{WO}_{3}$ $[1,1,2]$ and $\mathrm{c}-\mathrm{WO}_{3}[1,3,2]$ are illustrated in Fig. 2(b) and Fig. 2(c).

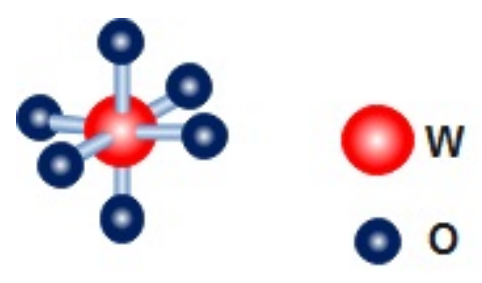

FIG. 1. A 3-D structure of $\mathrm{WO}_{3}$ molecule

Observe that, $\mathrm{c}-\mathrm{WO}_{3}[l, m, n]$ consist of 1,2 and 6 degrees vertices, and the total number of vertices are $4 l m n+$ $6 n+15(l n+m n)+l m+l+m+1$. Further, we partition the edge set of $\mathrm{c}-\mathrm{WO}_{3}[l, m, n]$ into two disjoint sub-classes with respect to the degrees of the end vertices of each edge namely, $\{1.6\}$ and $\{2,6\}$, and the total number of edges are $6 n(l m+l+m+1)$. In other words, all surface $\mathrm{O}$ atoms bound to $\mathrm{W}$ atoms can be shown by the edge type $E_{(1,6)}$ 
(a)

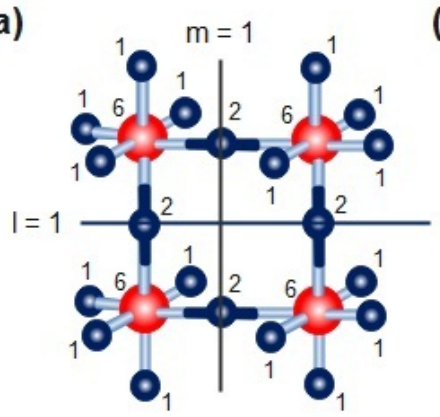

(b)

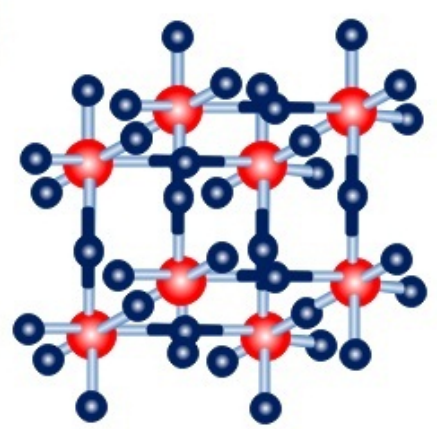

(c)

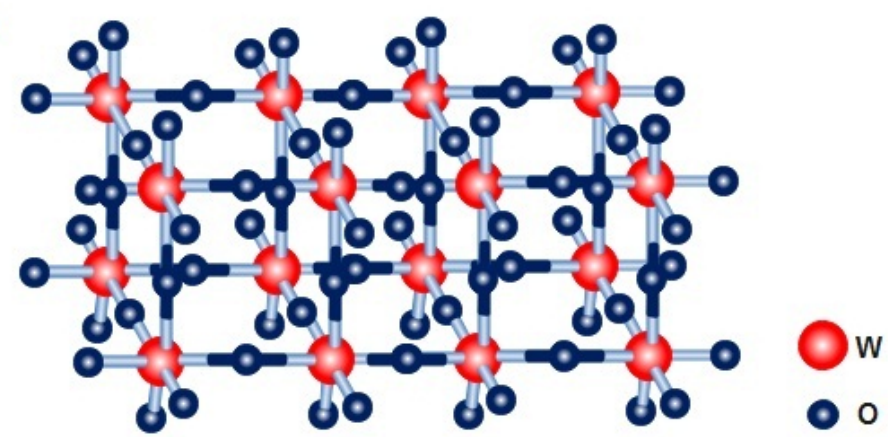

FIG. 2. (a) Vertices of $\mathrm{c}-\mathrm{WO}_{3}[1,1,1]$ labelled with degrees $\{1,2,6\}$; (b) $\mathrm{c}-\mathrm{WO}_{3}[1,1,2]$ and (c) $\mathrm{c}-\mathrm{WO}_{3}[1,3,2]$ nanomultilayer
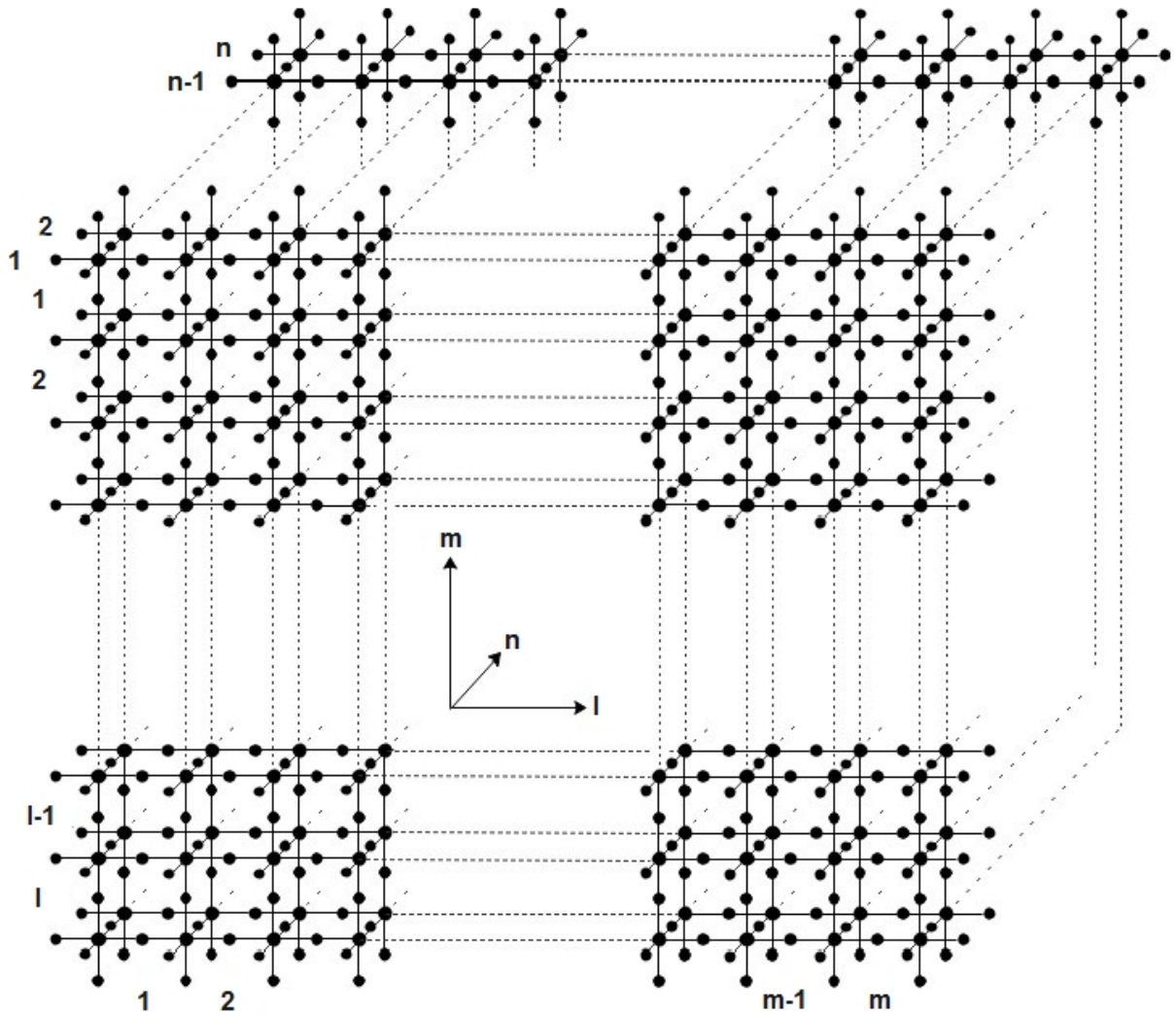

FIG. 3. Molecular graph of cubic $-\mathrm{WO}_{3}[l, m, n]$ nanomultilayer 
TABLE 1. Edge partition of $\mathrm{c}-\mathrm{WO}_{3}[l, m, n]$ nanomultilayer based on the degree of end vertices of each edge

\begin{tabular}{|c|c|c|}
\hline Type of edges & $E_{(1,6)}$ & $E_{(2,6)}$ \\
\hline$\left(d_{u}, d_{v}\right), u, v \in E(G)$ & $(1,6)$ & $(2,6)$ \\
\hline $\begin{array}{c}\text { Number of Edges } \\
\mid E_{\left(d_{u}, d_{v}\right)}\end{array}$ & $2(l m+m n+l n+l+m+2 n+1)$ & $\begin{array}{c}6 l m n+4(l n+m n)+2 n- \\
2(l m+l+m+1)\end{array}$ \\
\hline
\end{tabular}

TABLE 2. Vertex partition of $\mathrm{c}-\mathrm{WO}_{3}[l, m, n]$ nanomultilayer based on the degree of end vertices of each edge

\begin{tabular}{|c|c|c|c|}
\hline $\begin{array}{c}\text { Vertex } \\
\text { partition } V_{d_{u}}\end{array}$ & $V_{1}$ & $V_{2}$ & $V_{6}$ \\
\hline$d_{u}, u \in V(G)$ & 1 & 2 & 6 \\
\hline $\begin{array}{c}\text { Number of } \\
\text { Vertices } \\
\left|V_{d_{u}}\right|\end{array}$ & $2(l m+m n+l n+l+m+2 n+1)$ & $\begin{array}{c}3 l m n+2(l n+m n)- \\
(l m+l+m+n+1)\end{array}$ & $(l m+l+m+1) n$ \\
\hline
\end{tabular}

and the intermediated $\mathrm{O}$ atoms connected with $\mathrm{W}$ atoms are represented by the edge type $E_{(2,6)}$. Table 1 and Table 2 represent the degree based edge partition and vertex partition of $\mathrm{c}-\mathrm{WO}_{3}[l, m, n]$.

The edge set $\mathrm{c}-\mathrm{WO}_{3}[l, m, n]$ nanomultilayer with $l, m, n \geq 1$ has following two partitions:

$$
E_{(1,6)}=\left\{e=u v \in E\left(\mathrm{c}-\mathrm{WO}_{3}[l, m, n]\right) \mid d_{u}=1, d_{v}=6\right\}
$$

and

$$
E_{(2,6)}=\left\{e=u v \in E\left(\mathrm{c}-\mathrm{WO}_{3}[l, m, n]\right) \mid d_{u}=2, d_{v}=6\right\} .
$$

The vertex set of $\mathrm{c}-\mathrm{WO}_{3}[l, m, n]$ nanomultilayer with $l, m, n \geq 1$ has following three partitions:

$$
V_{1}=\left\{v \in V\left(\mathrm{c}-\mathrm{WO}_{3}[l, m, n]\right) \mid d_{v}=1\right\}, \quad V_{2}=\left\{v \in V\left(\mathrm{c}-\mathrm{WO}_{3}[l, m, n]\right) \mid d_{v}=2\right\}
$$

and

$$
V_{6}=\left\{v \in V\left(\mathrm{c}-\mathrm{WO}_{3}[l, m, n]\right) \mid d_{v}=6\right\} .
$$

\section{Main results}

Theorem 3.1. Let c- $\mathrm{WO}_{3}[l, m, n]$ be the cubic structured $\mathrm{WO}_{3}$ nanomultilayer of dimensions $l, m$, and $n \geq 1$. Then

$$
\begin{aligned}
& \mathrm{SCI}\left(\mathrm{c}-\mathrm{WO}_{3}[l, m, n]\right)=\chi\left(\mathrm{c}-\mathrm{WO}_{3}[l, m, n]\right)= \\
& \quad \frac{2(l m+m n+n l+l+m+2 n+1)}{\sqrt{7}}+\frac{6 l m n+4(l n+m n)+2 n-2(l m+l+m+1)}{2 \sqrt{2}} .
\end{aligned}
$$

$$
\chi_{\alpha}\left(\mathrm{c}-\mathrm{WO}_{3}[l, m, n]\right)=2(l m+m n+n l+l+m+2 n+1)(7)^{\alpha}+
$$

$$
(6 l m n+4(l n+m n)+2 n-2(l m+l+m+1))(8)^{\alpha} .
$$

$$
\begin{aligned}
\mathrm{SEI}_{\alpha}\left(\mathrm{c}-\mathrm{WO}_{3}[l, m, n]\right)=2 \alpha(l m+m n+n l+l+m+2 n+1)+ \\
\alpha^{2}(3 l m n+2(l n+m n)-(l m+l+m+n+1))+\alpha^{6}(l m+l+m+1) n,
\end{aligned}
$$

where $\alpha$ is any positive real number such that $\alpha \neq 1$. 
(4)

$\mathrm{ABC}\left(\mathrm{c}-\mathrm{WO}_{3}[l, m, n]\right)=2 \sqrt{\frac{5}{6}}(l m+m n+n l+l+m+2 n+1)+$

$$
\sqrt{\frac{1}{2}}(6 l m n+4(l n+m n)+2 n-2(l m+l+m+1)) .
$$

$\mathrm{H}\left(\mathrm{c}-\mathrm{WO}_{3}[l, m, n]\right)=\frac{4}{7}(l m+m n+n l+l+m+2 n+1)+$

$$
\frac{1}{4}(6 l m n+4(\ln +m n)+2 n-2(l m+l+m+1)) .
$$

$\operatorname{OGA}\left(\mathrm{c}-\mathrm{WO}_{3}[l, m, n]=\frac{4 \sqrt{6}}{7}(l m+m n+n l+l+m+2 n+1)+\right.$

$$
\frac{\sqrt{3}}{2}(6 l m n+4(\ln +m n)+2 n-2(l m+l+m+1)) \text {. }
$$

(7) $\mathrm{SK}\left(\mathrm{c}-\mathrm{WO}_{3}[l, m, n]\right)=24 l m n+23(l n+m n)+(22 n-l m)-(l+m+1)$.

(8) $\mathrm{SK}_{1}\left(\mathrm{c}-\mathrm{WO}_{3}[l, m, n]\right)=36 l m n+30(l n+m n)+6(4 n-l m)-6(l+m+1)$.

(9) $\mathrm{SK}_{2}\left(\mathrm{c}-\mathrm{WO}_{3}[l, m, n]\right)=96 l m n+88.5(l n+m n)+(81 n-7.5 l m)-7.5(l+m+1)$.

(10) $\mathrm{F}\left(\mathrm{c}-\mathrm{WO}_{3}[l, m, n]\right)=240 l m n+234(l n+m n)+6(38 n-l m)-6(l+m+1)$.

(11) $\mathrm{SDD}\left(\mathrm{c}-\mathrm{WO}_{3}[l, m, n]\right)=20 l m n+\frac{77}{3}(l n+m n)+\frac{1}{3}(94 n+17 l m)+\frac{17}{3}(l+m+1)$.

(12) $\mathrm{AZI}\left(\mathrm{c}-\mathrm{WO}_{3}[l, m, n]\right)=48 l m n+35.456(l n+m n)+(22.912 n-12.544 l m)-12.544(l+m+1)$.

(13) $\operatorname{ISI}\left(\mathrm{c}-\mathrm{WO}_{3}[l, m, n]\right)=9 l m n+7.714(l n+m n)+1.29(5 n-l m)-1.29(l+m+1)$.

(14) $\operatorname{IRM}\left(c-\mathrm{WO}_{3}[l, m, n]\right)=96 l m n+114(l n+m n)+(132 n-18 l m)+18(l+m+1)$.

(15) ${ }^{m} M_{2}\left(\mathrm{c}-\mathrm{WO}_{3}[l, m, n]\right)=\left(\frac{1}{6}\right)(3 \operatorname{lm} n+4(\ln +m n)+(5 n+l m)+(l+m+1))$.

$$
\begin{aligned}
R R_{\alpha}\left(\mathrm{c}-\mathrm{WO}_{3}[l, m, n]\right)= & \frac{2}{(6)^{\alpha}}(l m+m n+n l+l+m+2 n+1)+ \\
& \frac{1}{(12)^{\alpha}}(6 \operatorname{lm} n+4(\ln +m n)+2 n-2(\operatorname{lm}+l+m+1)) .
\end{aligned}
$$

(17) $A\left(\mathrm{c}-\mathrm{WO}_{3}[l, m, n]\right)=24 l m n+26(l n+m n)+2(14 n+l m)+2(l+m+1)$.

$$
\begin{aligned}
& B\left(\mathrm{c}-\mathrm{WO}_{3}[l, m, n]\right)= \\
& 2(l m+m n+n l+l+m+2 n+1)\left(1-\frac{12 n(l m+l+m+1)}{4 l m n+6 n+15(l n+m n)+l m+l+m+1}\right)^{2}+ \\
& (3 \operatorname{lm} n+2(l n+m n)-(l m+l+m+n+1))\left(2-\frac{12 n(l m+l+m+1)}{4 l m n+6 n+15(\ln +m n)+l m+l+m+1}\right)^{2}+ \\
& (l m+l+m+1) n\left(6-\frac{12 n(l m+l+m+1)}{4 l m n+6 n+15(l n+m n)+l m+l+m+1}\right)^{2} .
\end{aligned}
$$

Proof. One can make calculations in accordance with the rules presented in Table 3.

\section{Index analysis and description}

In this part, we present index analysis of computed indices of cubic $\mathrm{WO}_{3}[l, m, n]$ nanomultilayer. Fig. 4(a) suggests that IRM, Albertson and Bell indices are linearly related with number of vertices in nanomultilayer of dimensions $l, m$ and $n$. These three indices really correlate the tendency of irregularity in structure [27,30,31]. However $B(G)$ progresses very slowly. On the other hand, $\operatorname{IRM}(G)$ increases sharply, indicating that the nanomultilayer structure becomes more irregular and complex as dimension increases. The graph in Fig. 4(b) illustrates the dependence of $\operatorname{ABC}(G), \operatorname{OGA}(G)$ and $\operatorname{AZI}(G)$ on nanomultilayer dimension. It is now an established fact that, these indices are more sensitive to predict thermodynamic properties of compounds $[18,21,25]$. 
TABLE 3. Formula for degree-based topological indices of a graph $G$

\begin{tabular}{|c|c|c|c|}
\hline S. No & Topological Index & Notation & Formula of Topological Index \\
\hline 1. & $\begin{array}{l}\text { Sum Connectivity } \\
\text { Index [14] }\end{array}$ & $\operatorname{SCI}(G)=\chi(G)$ & $\sum_{u \in E(G)} \frac{1}{\sqrt{d_{u}+d_{v}}}$ \\
\hline 2. & $\begin{array}{c}\text { General Sum } \\
\text { Connectivity Index [15] }\end{array}$ & $\chi_{\alpha}(G)$ & $\sum_{u \in E(G)}\left(d_{u}+d_{v}\right)^{\alpha}$ \\
\hline 3. & $\begin{array}{c}\text { Variable Sum } \\
\text { exdeg Index }[16,17]\end{array}$ & $\operatorname{SEI}_{\alpha}(G)$ & $\sum_{u \in V(G)} d_{u}(\alpha)^{d_{u}}$, and $\alpha \neq 1$ \\
\hline 4. & $\begin{array}{l}\text { Atomic Bond } \\
\text { Connectivity } \\
\text { Index [18] }\end{array}$ & $\operatorname{ABC}(G)$ & $\sum_{u \in E(G)} \sqrt{\frac{d_{u}+d_{v}-2}{d_{u} \cdot d_{v}}}$ \\
\hline 5. & $\begin{array}{c}\text { Harmonic } \\
\text { Index }[19,20]\end{array}$ & $H(G)$ & $\sum_{u \in E(G)} \frac{2}{d_{u}+d_{v}}$ \\
\hline 6. & $\begin{array}{l}\text { Ordinary Geometric } \\
\text { Arithmetic Index [21] }\end{array}$ & $\operatorname{OGA}(G)$ & $\sum_{u \in E(G)} \frac{2 \sqrt{d_{u} \cdot d_{v}}}{d_{u}+d_{v}}$ \\
\hline 7. & SK Index [22] & $\operatorname{SK}(G)$ & $\sum_{u \in E(G)} \frac{d_{u}+d_{v}}{2}$ \\
\hline 8. & $\mathrm{SK}_{1}$ Index [22] & $\operatorname{SK}_{1}(G)$ & $\sum_{u \in E(G)} \frac{d_{u} \cdot d_{v}}{2}$ \\
\hline 9. & $\mathrm{SK}_{2}$ Index [22] & $\operatorname{SK}_{2}(G)$ & $\sum_{u \in E(G)}\left(\frac{d_{u}+d_{v}}{2}\right)^{2}$ \\
\hline 10. & Forgotten Index [23] & $F(G)$ & $\sum_{u}\left[\left(d_{u}\right)^{2}+\left(d_{v}\right)^{2}\right]$ \\
\hline 11. & $\begin{array}{l}\text { Symmetric Division } \\
\text { (Deg) Index [24] }\end{array}$ & $\operatorname{SDD}(G)$ & $\sum_{u \in E(G)}\left[\frac{\min \left\{d_{u}, d_{v}\right\}}{\max \left\{d_{u}, d_{v}\right\}}+\frac{\max \left\{d_{u}, d_{v}\right\}}{\min \left\{d_{u}, d_{v}\right\}}\right]$ \\
\hline 12. & $\begin{array}{l}\text { Augmented Zagreb } \\
\text { Index [25] }\end{array}$ & $\operatorname{AZI}(G)$ & $\sum_{u \in E(G)}\left(\frac{d_{u} \cdot d_{v}}{d_{u}+d_{v}-2}\right)^{3}$ \\
\hline 13. & $\begin{array}{l}\text { Inverse sum (Indeg) } \\
\text { Index [26] }\end{array}$ & $\operatorname{ISI}(G)$ & $\sum_{u \in E(G)} \frac{d_{u} \cdot d_{v}}{d_{u}+d_{v}}$ \\
\hline 14. & IRM Index [27] & $\operatorname{IRM}(G)$ & $\sum_{u \in E(G)}\left(d_{u}-d_{v}\right)^{2}$ \\
\hline 15. & $\begin{array}{l}\text { Modified Second } \\
\text { Zagreb Index [28] }\end{array}$ & ${ }^{m} M_{2}(G)$ & $\sum_{u \in E(G)} \frac{1}{d_{u} \cdot d_{v}}$ \\
\hline 16. & $\begin{array}{l}\text { Inverse Randić } \\
\text { Index [29] }\end{array}$ & $R R_{\alpha}(G)$ & $\sum_{u} \frac{1}{\left(d_{u} \cdot d_{v}\right)^{\alpha}}$ \\
\hline 17. & Albertson Index [30] & $A(G)$ & $\sum_{u \in \in E(G)}\left|d_{u}-d_{v}\right|$ \\
\hline 18. & Bell Index [31] & $B(G)$ & $\sum_{u \in V(G)}\left(d_{u}-\frac{2 q}{p}\right)^{2}$ \\
\hline
\end{tabular}


(a)

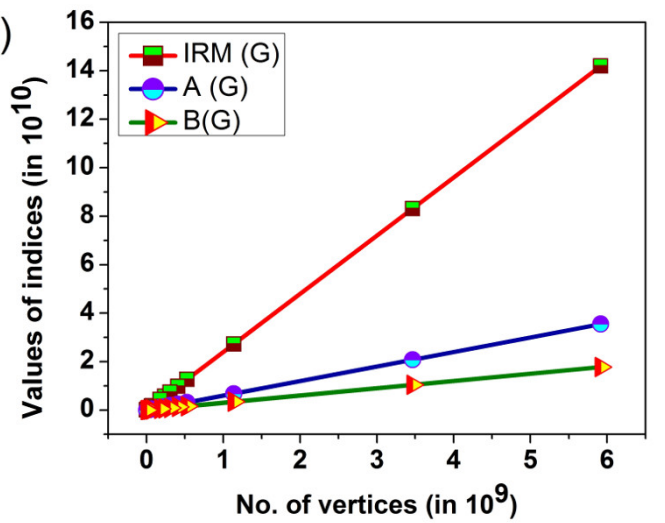

(c)

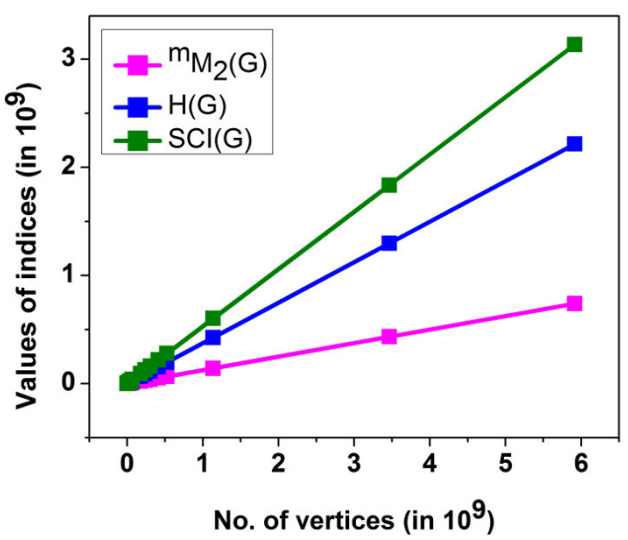

(b)

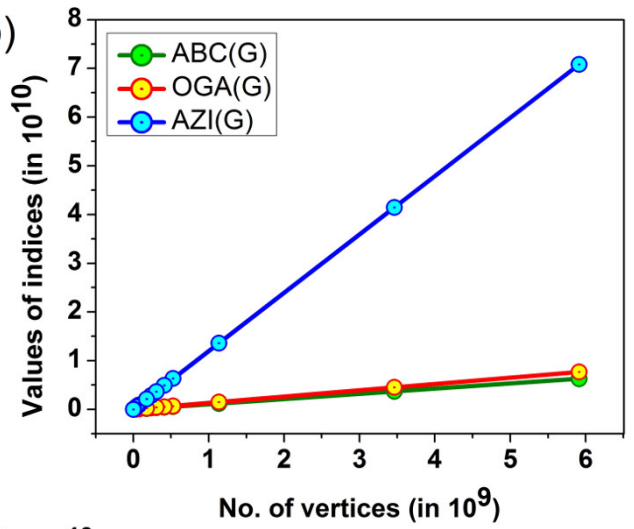

(d)

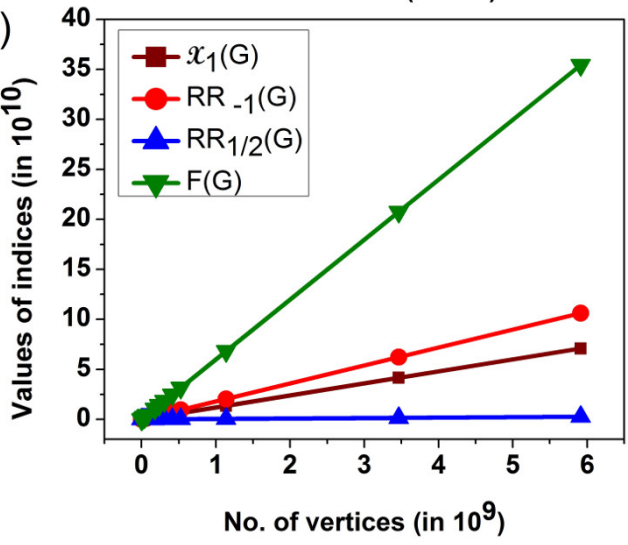

FIG. 4. Comparison of values of different topological indices (a) $\operatorname{IRM}(G), A(G)$ and $B(G)$; (b) $\operatorname{ABC}(G), \operatorname{OGA}(G)$ and $\operatorname{AZI}(G)$; (c) ${ }^{m} M_{2}(G), H(G)$ and $\mathrm{SCI}(G)$ and (d) $\chi_{1}(G), R R_{-1}(G)$, $R R_{1 / 2}(G)$ and $F(G)$ with respect to number of vertices in c- $\mathrm{WO}_{3}[l, m, n]$ nanomultilayer

The indices graphically represented in Fig. 4(c) and Fig. 4(d) are actually related with the total $\pi$ electron energy of compounds $[14,15,19,20,28,29]$. Clearly, Forgotten index responds promptly as compared to other indices, suggesting that which has the higher prediction capacity of this energy. It is evident from Fig. 4(c) that, ${ }^{m} M_{2}(G)$ has the least prediction potential with respect to the dimension. The indices plotted in Fig. 5(a) are considered to predict the total surface area of a structure $[24,26]$. The prediction performance of $\operatorname{SDD}(G)$ is greater than $\operatorname{ISI}(G)$. Fig. 5(b) and Fig. 6 clearly show that, $S K_{2}(G)$ increases quickly as a function of dimensions $[l, m, n]$.

(a)

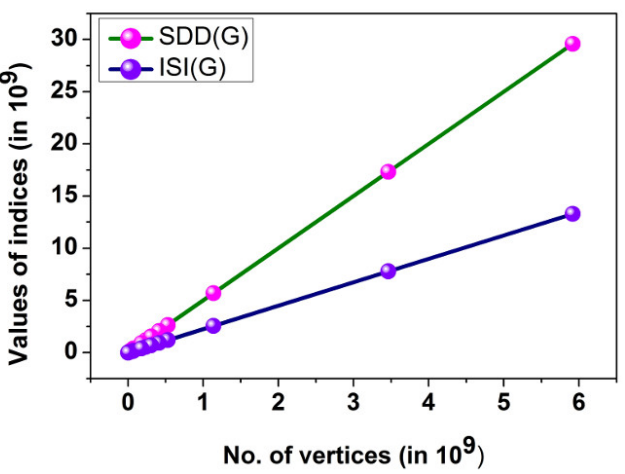

(b)

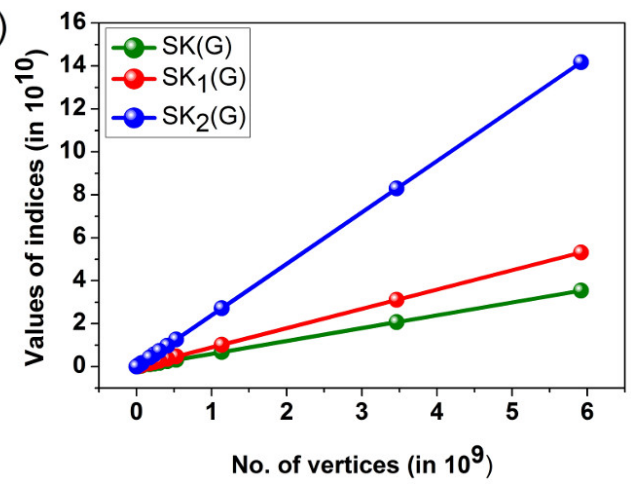

FIG. 5. Comparison of the topological indices (a) $\operatorname{SDD}(G)$ and $\operatorname{ISI}(G)$; (b) $\operatorname{SK}(G), \mathrm{SK}_{1}(G)$ and $\mathrm{SK}_{2}(G)$ with respect to number of vertices in c-WO $[l, m, n]$ nanomultilayer 


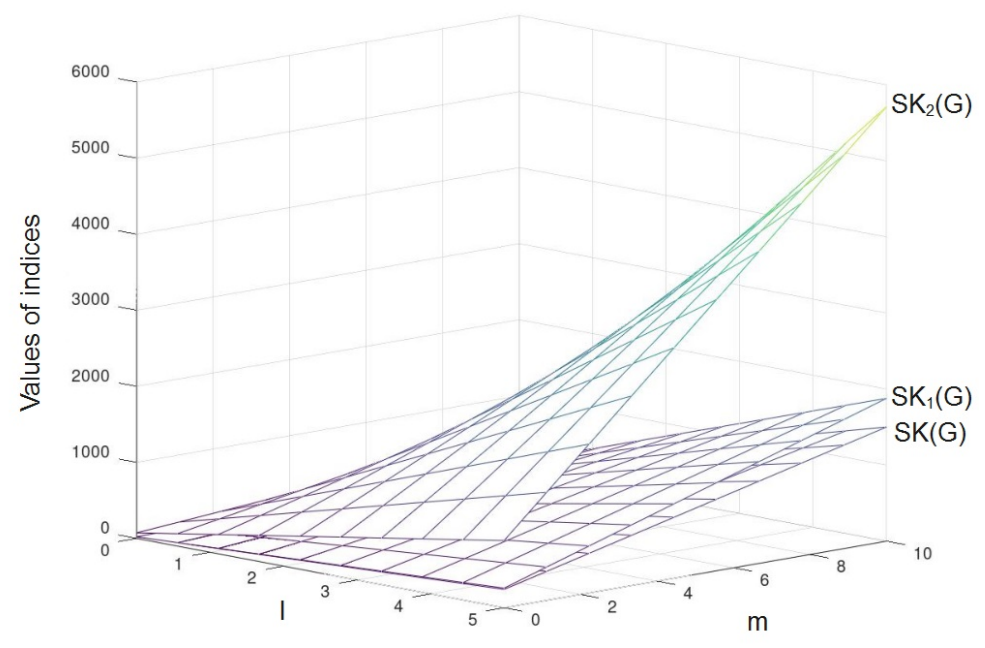

FIG. 6. A 3-D surface plot showing the comparison of $\operatorname{SK}(G), \operatorname{SK}_{1}(G)$ and $\operatorname{SK}_{2}(G)$ indices with respect to number of vertices in $\mathrm{c}^{-\mathrm{WO}_{3}}[l, m, n]$ monolayer; where $l \in[1,5]$ and $m \in[1,10]$ using Octave software

\section{Conclusion}

We successfully computed some important degree based topological indices for cubic structured $\mathrm{WO}_{3}[l, m, n]$ nanomultilayer and accurate expressions have been obtained. We also presented index analysis graphically with a view to understand the dependence on the involved parameters $[l, m, n]$. From an applicative point of view, the indices reported in this literature are really correlated with physicochemical properties of $\mathrm{WO}_{3}$ nanomultilayer and will be helpful for people employed within nanotechnology industries.

\section{References}

[1] West D.B. Introduction to Graph Theory, 2nd Edition, Prentice Hall, 2000.

[2] Wiener H.J. Structural determination of paraffin boiling points. Journal of the American Chemical Society, 1947, 69 (1), P. 17-20.

[3] Gutman I., Trinajstic N. Graph theory, and molecular orbitals total f-electron energy of alternant hydrocarbons. Chem. Phys. Lett., 1972, 17, P. 535-538.

[4] Rucker G., Rucker C. On topological indices, boiling points, and cycloalkanes. J. Chem. Inf. Comput. Sci., 1999, 39, P. 788.

[5] Gutman I. Molecular graphswith minimal andmaximal Randic indices. Croatica Chem. Acta., 2002, 75, P. 357-369.

[6] Gutman I. Degree-based topological indices. Croat. Chem. Acta., 2013, 86, P. 351-361.

[7] Dearden J.C. The Use of Topological Indices in QSAR and QSPR Modeling. In: Advances in QSAR Modeling. Challenges and Advances in Computational Chemistry and Physics, Roy K. (ed.), 2017, 24, P. 57-88.

[8] Samir A. Senior, Magdy D. Madbouly., Abdel-Moneim Elmassry. QSTR of the toxicity of some organophosphorus compounds by using the quantum chemical and topological descriptors. Chemosphere, 2011, 85 (1), P. 7-12.

[9] Fei Deng, Xiujun Zhang, et al. Topological Indices of the Pent-Heptagonal Nanosheets $\mathrm{VC}_{5} \mathrm{C}_{7}$ and $\mathrm{HC}_{5} \mathrm{C}_{7}$. Advances in Materials Science and Engineering, 2019, 9594549.

[10] Munir M., Nazeer W., Rafique S., Kang S.M. MPolynomial and Degree-Based Topological Indices of Polyhex Nanotubes. Symmetry, 2016, 8 (12), P. 149

[11] Munir M., Nazeer W., Rafique S., Kang S.M. Mpolynomial and degree- based topological indices of Nano star dendrimers. Symmetry, 2016, 8 (9), P. 97.

[12] Diudea M.V., Gutman I., Lorentz J. Molecular topology, Nova Science Publishers, Huntington, NY, 2001.

[13] Trinajstic N. Chemical Graph theory, CRC Press, Boca Raton, 1992.

[14] Zhou B., Trinajstić N. On a novel connectivity index. J. Math. Chem., 2009, 46, P. 1252-1270.

[15] Zhou B., Luo W. A note on general Randic index. Match Commun. Math. Comput. Chem., 2009, 62, P. $155-162$.

[16] Vukičević D. Bond Additive Modeling 4. QSPR and QSAR studies of the variable Adriatic indices. Croat. Chem. Acta., 2011, 84 (1), P. 87-91.

[17] Vukičević D. Bond additive modeling 5. mathematical properties of the variable sum exdeg index. Croat. Chem. Acta., 2011,84 (1), P. $93-101$.

[18] Estrada E., Torres L., Rodriguez L., Gutman I. An atom-bond connectivity index: modelling the enthalpy of formation of alkanes. Indian Journal of Chemistry, 1998, 37A, P. 849-855.

[19] Favaron O., Maheó M., Saclé J.-F. Some eigenvalue properties in graphs (conjectures of graffiti-II). Discrete Mathematics, 1993, 111 (1-3), P. 197-220.

[20] Fajtlowicz S. On conjectures of graffiti-ii. Congr. Numer., 1987, 60, P. 187-197.

[21] Vukičević D., Furtula B. Topological index based on the ratios of geometrical and arithmetical means of end-vertex degrees of edges. J. Math. Chem., 2009, 46, P. 1369-1376.

[22] Shigehalli V.S., Kanabur R. Computation of new degree-based topological indices of graphene. Journal of Nanomaterials, $2016,4341919$. 
[23] Furtula B., Gutman I. A forgotten topological index. J. Math. Chem., 2015, 53, P. 184-1190.

[24] Vukičević D., Gašperov M. Bond additive modeling 1. Adriatic indices. Croatica Chemica Acta, 2010,83 (3), P. $243-260$.

[25] Furtula B., Graovac A., Vukičcević D. Augmented zagreb index. Journal of Mathematical Chemistry, 2010,48 (2), P. 370-380.

[26] Sedlar J., Stevanović D., Vasilyev A. On the inverse sum indeg index. Discrete Applied Mathematics, 2015, 184, P. $202-212$.

[27] Hamzeh A., Réti T. An Analogue of Zagreb Index Inequality Obtained from Graph Irregularity Measures. Match Commun. Math. Comput. Chem., 2014, 72, P. 669-683.

[28] Miličević A., Nikolić S., Trinajstić N. On reformulated zagreb indices. Molecular Diversity, 2004, 8, P. $393-399$.

[29] Amić D., Bešlo D., et al. The vertex-connectivity index revisited. Journal of Chemical Information and Computer Sciences, 1998, 38 (5), P. 819-822.

[30] Albertson M. The irregularity of a graph. Ars. Combin., 1997, 46, P. 219-225.

[31] Bell F. A note on the irregularity of graphs. Linear Algebra Appl., 1992, 161, P. 45-54.

[32] Randić M. Characterization of molecular branching. Journal of the American Chemical Society, 1975,97 (23), P. $6609-6615$.

[33] Haidong Zheng, Jian Zhen Ou, et al. Nanostructured Tungsten Oxide-Properties, Synthesis, and Applications. Adv. Funct. Mater., 2011, 21, P. 2175-2196.

[34] Liu X., Wang F., Wang Q. Nanostructure-based WO3 Photoanodes for Photoelectrochemical Water Splitting. Phys. Chem. Chem. Phys., 2012, 14, P. 7894-7911.

[35] Chang-Mou Wu., Saba Naseem, et al. Recent Advances in Tungsten-Oxide-Based Materials and Their Applications. Front. Mater., 2019, 6 (49), P. 1-17.

[36] Jijie Zhang, Peng Zhang, Tuo Wang, Jinlong Gong. Monoclinic $\mathrm{WO}_{3}$ nanomultilayers with preferentially exposed (002) facets for photoelectrochemical water splitting. Nano Energy, 2015, 11, P. 189-195. 